\title{
Active Community Screening in a High COVID-19 Outbreak Area: A Short Note
}

\author{
Rujittika Mungmunpuntipantip ${ }^{a}$ Viroj Wiwanitkti ${ }^{b, c}$

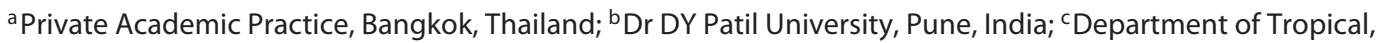 \\ Hainan Medical University, Haikou, China
}

\section{Dear Editor,}

COVID-19 presently affects more than 200 countries around the world and becomes one of the most serious health disasters in history. As a highly contagious disease, the disease could easily be transmitted and cause rapid spread around the world within 3 months after its emergence in the Republic of China in December 2019. The screening of the disease is an important tool in preventive medicine against the new disease. Generally, the disease is usually spread at an international airport or community places (such as railway stations and department stores). Nevertheless, this practice is not an active screening that directly seeks the hidden asymptomatic patients within the community [1].

Here, the authors share and analyze public data from Thailand, the second country that this new disease occurred in the chronological timeline [2]. The patients are usually not severe cases and there are some asymptomatic carriers. Adults are the most affected age group. Since the outbreak is hard to control, a new concept using active community COVID-19 case search was set up by the Thai CDC (referring to local public post data, https://www. hfocus.org/content/2020/04/18963).

At first, screening has been implemented since the first week of April 2020 in the area with an extremely high incidence of the disease, i.e. the beach resort area in the Phuket province. In this province, based on updated local data of 2nd May 2020 (referring to local public post data, https://www.thansettakij.com/content/432563), there were overall 220 cases with 3 deaths (fatality rate $=1.36 \%$ ). The local testing methodology employed for contact tracing is molecular RT-PCR testing by nasopharyngeal viral swab. Based on the local update data (referring to local public post data, https://www.thansettakij.com/content/432563), the active screening could cover 24,035 local people and there were 88 COVID-19 cases $(2.18 \%$, $85 \%$ confidence interval $=1.77-2.68 \%)$. It showed that there was a high rate of hidden COVID-19 cases in the community. Without active community screening, the silent carriers might cause continuous hot foci in this area. There is definitely an advantage of an active COVID-19 screening program. Nevertheless, it should not forget that the screening has to be carefully done. Protection of screening team is necessary to avoid getting disease from silent COVID-19 in the community.

\section{Conflict of Interest Statement}

The authors have no conflict of interest to declare.

$\begin{aligned} \text { References } \quad & \text { COVID-19 National Emergency Response } \\ & \text { Center, Epidemiology and Case Management } \\ & \text { Team, Korea Centers for Disease Control and } \\ & \text { Prevention. Coronavirus Disease-19: Summa- } \\ & \text { ry of 2,370 Contact Investigations of the First } \\ & 30 \text { Cases in the Republic of Korea. Osong Pub- } \\ & \text { lic Health Res Perspect. 2020 Apr;11(2):81-4. } \\ 2 & \text { Yasri S, Wiwanitkit V. Editorial: Wuhan } \\ & \text { coronavirus outbreak and imported case. Adv } \\ & \text { Trop Med Public Health Int. 2019;9:1-2. }\end{aligned}$

